\title{
Sistema de Classificação Bibliográfica e a conceituação do turismo: uma visão da CDU
}

\author{
Christiane Fabíola Momm
}

\begin{abstract}
Bacharel em Turismo.Pós-graduada em Planejamento e Gestão do Turismo Mestre pelo Programa de Pós-Graduação em Ciência da Informação - PGCIN da Universidade Federal de Santa Catarina - UFSC.
\end{abstract}

Rafael Orivaldo Lessa

\begin{abstract}
Bacharel em Sistemas de Informação. Mestrando do Programa de Pós-Graduação em Ciência da Informação - PGCIN da Universidade Federal de Santa Catarina - UFSC.
\end{abstract}

Aborda a inclusão da área de Turismo no Sistema de Classificação Decimal Universal (CDU), um dos mais importantes sistemas de classificação bibliográfica. Conceitos da área de Turismo subsidiaram uma análise das notações deste sistema e direcionaram uma discussão sobre a inserção da área na CDU. Objetiva analisar as classes em que o Turismo está inserido, por meio de pesquisa bibliográfica. Finaliza propondo uma revisão da CDU e a inclusão do Turismo como subclasse 379.

Palavras-chave: Sistema de Classificação; Classificação Decimal Universal; Turismo.

\section{Bibliographic Classification System and the concept of Tourism: a vision of the UDC}

The inclusion of the area of Tourism in the Universal Decimal Classification System (UDC), one of the most important bibliographic classification systems. Concepts of the Tourism area substantiated an analysis of the ratings system and directed a discussion about the inclusion of the area in the UDC. Seek to analyze the classes in which Tourism is inserted through bibliographic research. It finishes with a revision proposal of the UDC and the inclusion of the Tourism as subclass 379. 
Keywords: Classification System; Universal Decimal Classification; Tourism.

Recebido 24.02.2008 Aceito em 24.07.2009

\section{Introdução}

A diversidade de cursos superiores e disciplinas específicas oferecidos pelas Instituições de Ensino Superior (IES) em todo o Brasil propicia uma gama abrangente de alternativas para os estudantes que ingressam em cursos de graduação e de tecnologia com o intuito de adquirirem uma formação que atenda às necessidades e exigências do mercado de trabalho.

Dentre as diversas possibilidades, surgem os cursos nas áreas das ciências exatas, sociais, humanas, tecnológicas e da saúde, os quais refletem as necessidades mercadológicas e também científicas, bem como os interesses vinculados ao desenvolvimento de áreas específicas no país.

No Brasil, a criação de cursos superiores exige uma autorização prévia e a respectiva avaliação pelo Ministério da Educação (MEC), assim como observações referentes às regulamentações existentes em cada área.

Desta forma, com a implantação de novos cursos há a necessidade não só de se classificar os cursos em suas respectivas áreas do conhecimento, mas, também, de se refletir sobre os assuntos encontrados em classificações bibliográficas, essenciais para a elaboração e a realização de pesquisas acadêmicas e científicas.

Dentre os novos cursos superiores criados no Brasil, com um histórico recente de bibliografias disponíveis em língua portuguesa, encontra-se o curso de Turismo, cuja área é o objeto de análise deste artigo.

As classificações bibliográficas existentes possibilitam a representação dos assuntos, termos e conceitos das áreas do conhecimento, de seus cursos e disciplinas. Ao qualificarem as áreas do conhecimento, estas classificações têm como objetivo organizar os acervos de bibliotecas e facilitar a recuperação da informação por parte dos usuários.

O uso dessas classificações surge no momento da pesquisa teórica e leva o estudante a optar por fontes de informação para a realização da pesquisa na área escolhida.

Para que os assuntos relativos à área de Turismo sejam representados de forma apropriada, é necessário que as classificações bibliográficas reflitam os conceitos atuais do domínio em questão.

O objetivo deste artigo é verificar como ocorre a inclusão desta área no Sistema de Classificação Decimal Universal (CDU), que possibilita a representação de assuntos complexos e de classes diferentes por meio de mecanismos de combinação e incorporação do princípio de análise por facetas, princípio que permite uma análise multidimensional dos assuntos. 
Do ponto de vista metodológico, será analisada a área de Turismo, representada na CDU, tomando-se como ponto de partida conceitos básicos definidos por autores de referência da área.

\section{Classificação}

Os seres humanos classificam a todo o momento pessoas, objetos e animais, ou seja, tudo com o que o homem interage no seu dia-a-dia. Nossas ações no mundo são envolvidas por atos classificatórios. Conforme afirma Costa:

Encontramos inúmeros exemplos de classificações inscritas e atuantes nos mais variados domínios das relações sociais, tal como se nos apresentam no quotidiano. Basta pensar na maneira como as pessoas tratam umas as outras, ou se referem a terceiras, atribuindo estatutos de superioridade ou inferioridade social, considerando umas distintas e outras vulgares, umas sérias e outras desonestas, umas competentes e outras incapazes, umas merecedora de mais respeito e outras menos, e por aí afora (COSTA, 1997/98, p.66).

Para a classificação do conhecimento não seria diferente. Os sistemas de classificação bibliográfica surgiram com o objetivo de organizar acervos, de modo a facilitar a recuperação da informação. Trata-se de um bom instrumento de trabalho para bibliotecários consultarem no processo de classificação do acervo de uma biblioteca.

Dentre os sistemas de classificação bibliográfica propostos, está o de autoria de Melvil Dewey, que utilizou como referência o sistema proposto por William Torrey Harris e cuja denominação é Classificação Decimal de Dewey (CDD). A CDD, que divide o conhecimento humano em dez classes, foi a primeira das classificações bibliográficas. Este sistema influenciou a construção de outros importantes esquemas.

Com base na CDD e na noção de classificação facetada, foi elaborada a Classificação Decimal Universal (CDU), construída por Paul Otlet e Henri de La Fontaine. Com princípios da divisão científica do conhecimento, esta classificação trouxe, como avanço em relação à primeira, a possibilidade da representação de assuntos complexos e de classes diferentes por meio de mecanismos de combinação e incorporação do princípio de análise por facetas, o que permitiu uma análise multidimensional dos assuntos.

No Brasil, a CDU é o sistema de classificação bibliográfica mais utilizado, principalmente por bibliotecas que possuem documentos em áreas específicas.

A sua organização faz com que os documentos sejam alocados, obedecendo às diversas áreas de assuntos existentes e qualificáveis por suas tabelas. As tabelas são elaboradas com uma organização de conhecimentos. No entanto, atualmente esta organização nem sempre é a 
mais reconhecida, pois, com o desenvolvimento de novas áreas, ela acaba agregando equivocadamente assuntos em seções hierárquicas inapropriadas, apresentando, assim, relações incoerentes.

Tal sistema classifica principalmente as áreas interdisciplinares do conhecimento, como é o caso do Turismo. Muitas vezes, a classificação das novas áreas é equívoca, pois as mesmas são agrupadas com áreas que não estão de acordo com o tema.

\subsection{Classificação Decimal Universal}

A Classificação Decimal Universal (CDU) derivou-se da Classificação Decimal de Dewey (CDD) e pertencia, até o ano de 1991, ao que se denomina Federação Internacional de Informação e Documentação (FID), hoje absorvida pela Federação Internacional das Associações e Instituições Bibliotecárias (IFLA). No ano de 1992, o Consórcio CDU, formado por instituições de informação e normalização da Bélgica, Espanha, Países Baixos, Reino Unido e Japão, além da própria FID, começaram a atualizar a CDU (INSTITUTO BRASILEIRO DE INFORMAÇÃO, CIÊNCIA E TECNOLOGIA - IBICT, 1997).

Conforme descrito por Campos e Menezes (1992, p.16), "A CDU vem sendo divulgada através dos seguintes tipos de edição: desenvolvidas, média, abreviadas, condensadas e especiais, conforme a necessidade da classificação nas bibliotecas e centros de informações".

Para representar o conhecimento, a CDU configura-se como linguagem de indexação e recuperação da informação, que abrange praticamente todos os assuntos e que pode ser utilizada em acervos que lidam com qualquer tipo de suporte documental.

Com base na estrutura da CDU, Silva e Ganim (1994, p.11) consideram...

[...] uma concepção do universo do conhecimento e da informação como uma unidade, um todo constituído de partes intimamente relacionadas e interdependentes, cada qual representando uma parcela desse conhecimento. Estas parcelas, por sua vez, são suscetíveis de novas divisões e subdivisões, num processo teoricamente infinito, que constitui o caráter hierárquico (enumerativo) do sistema.

A CDU possui um esquema que se propõe a classificar todos os campos do conhecimento, sendo um sistema de conceitos hierarquicamente estruturado em dez grandes classes, destinado à classificação do conhecimento e dos suportes físicos de seu registro, a que denomina genericamente documentos: livros, folhetos, revistas, discos, fitas de áudio, discos fonográficos convencionais, discos laser, etc.

Silva e Ganim (1994, p.11) afirmam:

São essas dez classes e suas subdivisões hierárquicas que constituem a espinha dorsal do sistema e que correspondem 
por seu caráter aparentemente monolítico, rígido e inflexível. Há, entretanto, recursos divisados pelos idealizadores, e desenvolvidos pelos que Ihes sucederam, que permite suavizar com bastante eficácia essa característica supostamente negativa, fazendo com que o sistema assuma as feições hoje aclamadas como positivas pelos sistemas ditos facetados, multidimensionais ou poliierárquicos.

A CDU está organizada de modo a possibilitar a recuperação de todas as referências a partir de um assunto particular; assim, a informação pode ser localizada com o mínimo de esforço. Devido à sua notação internacional, independente de qualquer alfabeto ou língua, a CDU ajuda a minimizar as dificuldades de idioma na comunicação internacional, e pode prover uma base satisfatória até mesmo para a terminologia comparativa em vocabulários técnicos, glossários, etc.

Segundo 0 Instituto Brasileiro de Informação em Ciência e Tecnologia (IBICT) (1997, p. 3), na CDU "se refletiram e ainda se refletem os condicionantes sociais, filosóficos e técnicos [...], mas isso não significa que ela se manteve estática e cegamente obediente a esses condicionantes".

No Brasil, em 1900, Oswaldo Cruz introduziu a CDU na biblioteca do Instituto de Pesquisa que fundou e hoje tem o seu nome. Em 1911, o diretor-geral da Biblioteca Nacional criou o Serviço de Bibliografia e Documentação, em correspondência com o Instituto Internacional de Bibliografia de Bruxelas, segundo o ato que o regulamentou (ORTEGA, 2002).

Assim, a CDU está arraigada no terreno da biblioteconomia brasileira e é considerada um instrumento de trabalho eficiente para a organização da informação no país; tanto que a maioria das bibliotecas das Instituições de Ensino Superior (IES) do país utilizam tal classificação em seus acervos.

Atualmente, a versão utilizada no país data do ano de 1997 e, por seu sistema permitir a inclusão de praticamente todos os assuntos, as áreas do conhecimento já existentes e as recentes são incluídas neste sistema, permitindo maior facilidade e funcionalidade no momento de pesquisa acadêmica e científica.

Para melhor compreensão, destaca-se a apresentação tipográfica da CDU (edição em língua portuguesa da Edição-Padrão Internacional), conforme disposto pelo IBICT (1997). "Uma entrada na CDU consiste em três elementos principais: o número de classificação, que aparece na coluna de números à esquerda, a descrição da classe, que aparece na coluna de texto à direita, e várias explicações, que aparecem em composição recolhida na coluna de texto".

A estrutura da CDU está fundamentada em duas espécies de esquemas de classificação documentária: a enumerativa e a analíticosintética.

O destino final da CDU é o uso bibliográfico, e ela serve para a indexação e a descrição minuciosa do conteúdo de documentos que não 
se achem limitados a uma determinada coleção; razão de sua escolha pelas bibliotecas especializadas, por ser do tipo facetado. A CDU identifica características comuns a várias categorias e as organiza em listas ou tabelas que representam, cada uma, uma faceta, ou seja, a totalidade de conceitos obtidos mediante a aplicação de uma determinada característica de divisão. Assim, os assuntos são decompostos em seus elementos para recombinação ou síntese. Por este motivo, a classificação facetada é também chamada de analítico-sintética.

A CDU é o resultado de um projeto que aproveitou os pontos positivos de uma classificação enumerativa ajustando-os aos novos propósitos e, segundo Fontoura (2006), ,...

A natureza flexível da CDU tem sido o motivo de sua escolha como linguagem de indexação e recuperação da informação por parte de muitas bibliotecas e serviços de informação. Ela possibilita expressiva indexação e pesquisa pelos diferentes aspectos de um assunto, se adaptando a coleções multimídias. É particularmente eficiente para a organização e busca de informações na WEB.

Observa-se esta ocorrência por meio da notação, que é um código que representa os conceitos em uma classificação e que, em geral, expressa sua ordenação. No entanto, a notação correspondente aos conceitos deve possuir um valor ordinal inerente e próprio, expresso em algarismos arábicos.

Outro aspecto que deve ser considerado é que a CDU é composta por tabelas principais e auxiliares. A CDU (1997) compreende as seguintes classes: Etc.

0 Generalidades. Ciência e Conhecimento. Organização. Informação.

1 Filosofia. Psicologia.

2 Religião. Teologia.

Ciências Sociais... Direito. Administração. Etc.

Vaga.

5 Matemática. Ciências Naturais.

6 Ciências Aplicadas. Medicina. Tecnologia.

7 Arte. Belas-artes. Recreação. Diversões. Esportes.

8 Linguagem. Lingüística. Literatura.

9 Geografia. Biografia. História.

Por sua vez, cada uma dessas grandes classes pode ser dividida para formar outras dez classes, mais específicas. As subclasses apresentam conceitos mais restritos e podem ser representadas por números mais extensos como, por exemplo, mostrado no QUADRO 1, descrevendo o caso do Turismo.

QUADRO 1 Exemplo de conceitos da CDU

\section{Ciências Sociais}


30 Teoria das Ciências Sociais.

31 Demografia. Estatística. Sociologia.

32 Ciência Política.

33 Economia.

34 Direito.

35 Administração Pública.

36 Assistência Social. Seguros.

37 Educação. Pedagogia.

371 Organização do sistema de educação e ensino. Organização escolar.

372 Conteúdo e currículo na educação pré-escolar elementar.

373 Tipos de escola que ministram educação geral.

374 Educação e ensino fora da escola.

376 Educação, ensino, treinamento de grupos especiais de pessoas.

377 Ensino especializado. Instrução profissionalizante, técnica, profissional.

378 Educação superior.

379.8 Lazer.

379.85 Viagem de lazer, Turismo, Visitas a pontos turísticos.

39 Antropologia. Etnografia.

Fonte: Dados da pesquisa.

A CDU surgiu com um propósito inicial de organizar o documento para fomentar as redes sociais do saber. Passados 150 anos, os esquemas das estruturas de organização do conhecimento aumentaram e se modificaram. A CDU atual consta de 56.000 classes principais e mais de 13.000 classes auxiliares (UDC CONSORTIUM, 2007).

Todavia, a classe genérica que subsidiará a análise acerca da área do Turismo é a classe 3 Ciências Sociais... Direito. Administração. Etc., uma vez que o Turismo integra a grande área das Ciências Sociais e a classe 7 Arte. Belas-artes. Recreação. Diversões. Esportes.

No índice alfabético da CDU encontram-se, para fins de classificação, os descritores turismo; Turismo, política de; que estão classificados como 379.85 (Classe 3, grande área Ciências Sociais), 796.433.7 (Classe 7, grandes áreas Arte. Belas-artes. Recreação. Diversões. Esportes), 338.48 (Classe 3, grande área Ciências Sociais), respectivamente.

Verificando-se outra classe que agrega o turismo, observa-se que as grandes áreas são bastante abrangentes e associam o Turismo a atividade de Recreação. No entanto, especificamente essa notação da CDU aponta para um fator que contribui para a análise e a discussão propostas neste artigo.

A notação 796.433.7, que se encontra no índice, classifica o Turismo como Arremesso de outros objetos (p.ex.bolas, postes) (UDC CONSORTIUM, 1997/1998, p. 981), o que demonstra que os conceitos pressupõem uma revisão e uma classificação mais específica.

Por essa razão, serão explicitadas as definições propostas pela Organização Mundial de Turismo (OMT), por autores da área do Turismo, tanto internacional quanto nacional.

Uma análise feita por Lara (1993, p. 96) concluiu que a CDU não é um sistema flexível, uma vez que utiliza grades rígidas para a análise dos assuntos; fato que resulta na compartimentação das disciplinas e dificulta, 
por isso, a análise das áreas que possuem interdisciplinaridade. Como decorrência, a inclusão de novas disciplinas é feita de forma discutível, por subordinação nem sempre lógica e coerente, como ocorre com a área do Turismo.

A CDU ainda conta com as tabelas auxiliares, apresentando duas divisões: os sinais e as subdivisões auxiliares. O uso destas tabelas permite, além dos números simples, a construção de números compostos e sínteses, tornando, assim, a CDU mais flexível em relação à CDD.

Os sinais permitem a composição de números, atingindo um grau maior de especificidade e de recuperação da informação. Assim, a CDU possui ao todo cinco tipos de sinais, quais sejam:

1. Coordenação: representado pelo sinal de + (adição);

2. Extensão: representado pela / (barra oblíqua);

3. Relação: representado pelo sinal de : (dois pontos);

4. Subagrupamento: representado pelos [ ] (colchetes); e

5. Ordenação: representado pelos :: (dois pontos duplos).

\section{Turismo}

O turismo pode ser enfocado sob o ponto de vista da atividade turística voltada para o aspecto socioeconômico e como campo de estudo, enquanto área do conhecimento.

De acordo com o Ministério do Turismo (MTUR, 2006, p.21), "o turismo se destaca como um dos setores socioeconômicos mais significativos do mundo". Além disso, o turismo promove um intercâmbio de informações que abrangem desde a história até a cultura, tradições, costumes, gastronomia, dentre outras.

Enquanto campo de estudo, possui o enfoque direcionado para o meio acadêmico e científico e, segundo a Organização Mundial do Turismo (OMT,2001, p. 37), "o turismo como matéria de estudos universitários começou a interessar no período compreendido entre as duas grandes guerras mundiais (1919-1938)".

Por isso, o turismo é caracterizado como uma área multidisciplinar e interdisciplinar. A OMT (2001, p. 35) considera que...

Devido à relativa juventude do turismo como atividade socioeconômica em geral e a seu complexo caráter multidisciplinar (o turismo engloba uma grande variedade de setores econômicos e de disciplinas acadêmicas), há uma ausência de definições conceituais claras que delimitem a atividade turística e a distinga de outros setores.

No entanto, a OMT também afirma que não existe uma definição correta ou incorreta.

Como o turismo desenvolve-se de maneira gradual, faz-se necessário utilizar como referencial informações de cunho científico, que possam subsidiar e enfocar a realidade existente na área, no contexto atual. 
Conforme enfatiza Joncew (2005), as contribuições teóricas e práticas são dirigidas à academia, acreditando-se que ela deve estar sempre comprometida com o papel da informação na construção do desenvolvimento social sustentável.

Os primeiros trabalhos sobre turismo surgiram no início da década de 1870, e seu aparecimento na literatura foi vinculado à abordagem da geografia e da economia, não denotando ser uma área científica e, tampouco, de desenvolvimento científico. Porém, o turismo como uma área de estudos e de desenvolvimento científico ocorre, principalmente, após a $2^{a}$ Guerra Mundial, o que o caracteriza como uma área nova, na qual as profissões são ainda mais recentes (JOVICIC apud REJOWSKI, 1998).

Assim, por ser uma das áreas recentes, que produz informações e conhecimento, e que se destacou entre os cursos superiores oferecidos nas IES do país, a área de Turismo integra os cursos da grande área das Ciências Sociais Aplicadas.

\subsection{Turismo na CDU}

Quando comparada com outros sistemas de classificação, a classificação do Turismo na CDU possui um caráter flexível no que se refere aos temas e assuntos que agrega. Nesta classificação, as associações da área do Turismo ocorrem nas áreas das Ciências Sociais e estão inseridas, também, na grande área Arte, Belas-artes, Recreação, Diversões, Esportes.

No âmbito deste artigo, a análise do Turismo como subclasse na CDU será pautada pelos conceitos da Organização Mundial do Turismo (OMT) e dos autores Lickorish e Jenkins e Mário Carlos Beni. Com base nesses autores, será formulada uma definição síntese.

A OMT (2001, p. 38) descreve que "o turismo compreende as atividades que realizam as pessoas durante suas viagens e estadas em lugares diferentes ao seu entorno habitual, por um período consecutivo inferior a um ano, com finalidade de lazer, negócios ou outras".

Para Lickorish e Jenkins (2000, p. 9), "o turismo é uma atividade que ultrapassa os setores convencionais da economia. Ele requer dados de natureza econômica, social, cultural e ambiental. Nesse sentido, é freqüentemente descrito como uma atividade multifacetada".

Beni (2001, p. 34) ressalta que "pode-se identificar no campo acadêmico, nas empresas e nos órgãos governamentais três tendências para a definição de Turismo: a econômica, a técnica e a holística". E ainda complementa que "(...) em todo esforço para definir Turismo, faz-se necessário diferenciar 'conceito' de 'definições técnicas'" (p.36).

Além disso, Beni (2001, p.37) enfatiza:

Tenho conceituado Turismo como um elaborado e complexo processo de decisão sobre o que visitar, onde, como e a que preço. Nesse processo intervêm inúmeros fatores de realização pessoal e social, de natureza motivacional, 
econômica, cultural, ecológica e científica que ditam a escolha dos destinos, a permanência, os meios de transporte e o alojamento, bem como o objetivo da viagem em si [...], de enriquecimento existencial histórico-humanístico, profissional, e de expansão de negócios.

Como síntese, definiu-se que o turismo compreende as atividades que realizam as pessoas em suas viagens e envolve aspectos relacionados à natureza sócio-econômica, motivacional, cultural, ambiental, acadêmica, empresarial e governamental.

Diante das definições expostas e da síntese formulada verifica-se que, em um enfoque mais amplo, o turismo associa-se com as seguintes áreas:

1. Administração;

2. Direito;

3. Economia;

4. Educação;

5. Psicologia;

6. Sociologia;

7. Recreação.

A primeira notação de Turismo na CDU direciona-se para a subclasse 379.85 viagem de lazer; turismo; visitas a pontos turísticos, sendo classificada em nível hierárquico dentro da subclasse do lazer.

Porém, esta subclasse apresenta duas remissivas: uma para a subclasse 338.48, que se refere ao movimento de turismo do ponto de vista econômico e à política sobre indústria do turismo; e a outra direciona para a área de Recreação na subclasse 796.5, referente a excursionismo; marcha; montanhismo; esportes de orientação; acampamento.

Diante disso, pode-se dizer que o turismo está parcialmente contemplado na subclasse 338.48 apresentada na CDU, faltando associações com outros aspectos mais abrangentes da economia. No entanto, na subclasse 796.5 encontram-se associações compatíveis com algumas atividades vinculadas ao turismo, como 0 ecoturismo e o turismo de aventura, que compreendem o excursionismo e os esportes de orientação.

Enfatiza-se ainda a existência de uma outra notação para turismo, já exposta anteriormente, a qual se refere à subclasse Recreação 796.433.7, que inclui o Turismo como arremesso de outros objetos (p.ex.bolas, postes), demonstrando a incompatibilidade com a área, ou, ainda, apresentando um erro de remissiva expresso no índice da CDU.

Verifica-se que sob os enfoques da administração, direito, psicologia e sociologia, o turismo não está associado a estas áreas, enquanto subclasse dentro da CDU.

Considerando-se o caráter multi e interdisciplinar da área, as atualizações na CDU devem ocorrer em um intervalo inferior a 10 anos. Como se configura hoje, observam-se lacunas que não correspondem ao que se pode encontrar em materiais classificados pela CDU, como, por exemplo, a notação 380 não inclusa nas tabelas de classificação deste sistema. 
Uma alternativa para contemplar o turismo como subclasse principal seria adotar a notação 379 para os assuntos relacionados com a área. A classificação atual aponta o turismo como hierarquicamente pertencente à economia (33), educação (37), recreação (79). A disposição dessas hierarquias demonstra o turismo como secundário na CDU, tendo em vista que o mesmo não possui uma subclasse específica.

Sob outro aspecto, o turismo está condicionado ao lazer, indicando uma inferioridade enquanto atividade. Na realidade, sob o ponto de vista do turismo, um segmento seria o lazer e não o contrário, como disposto na CDU, considerando-se o caráter abrangente da atividade $e$ as definições fundamentadas em autores referência nesta área, apresentadas neste artigo.

A CDU, com as tabelas auxiliares, seus sinais e subdivisões auxiliares, permite o relacionamento entre as áreas. Por exemplo, se a notação adotada para o turismo fosse 379 poder-se-ia relacioná-lo da seguinte maneira:

1. 379 : 658 (Administração);

2. 379 : 34 (Direito);

3. 379 : 159 (Psicologia);

4. 379 : 316 (Sociologia).

Com esse relacionamento e a utilização dos sinais específicos, seria possível a associação com outras áreas do conhecimento, tornando a recuperação da informação mais ágil.

Para Lage e Milone (2000, p.105), "ao profissional de turismo é imperativo um nível superior de conhecimento para utilizar a informação e torná-la conseqüente e competitiva".

Por essa razão, faz-se necessária uma atualização contínua de tal modelo de representação do conhecimento, tendo em vista que este aspecto pode refletir na recuperação da informação por parte de pesquisadores da área de Turismo e de áreas correlatas.

\section{Considerações finais}

Diversas são as definições para o turismo enquanto campo de estudo e atividade socioeconômica, e muitos são os pesquisadores que atuam visando à formulação de definições que agreguem os aspectos referenciais da área.

O caráter multi e interdisciplinar possibilita interpretações e associações com outras áreas do conhecimento, e talvez por essa razão a CDU não enquadre o turismo em uma subclasse específica, apresentando0 , assim, subordinadamente em duas classes e respectivas subclasses.

Este aspecto também suscita algumas reflexões sobre a epistemologia do turismo, conforme afirmação de Panosso Netto (2003, p. 57): "dentre as questões que vêm afligindo os pesquisadores do turismo desde meados do século XX está a configuração, ou construção de uma 
epistemologia que se propusesse a explicar as bases do fenômeno ${ }^{1}$ turístico por meio de uma teoria que articulasse as suas (multi) facetas".

Diante das notações identificadas, ressalta-se a importância de incluir, na equipe de formulação da CDU, profissionais da área de turismo e de áreas correlatas, a fim de evitar contradições ou mesmo a inexistência do domínio em questão.

A OMT (2001, p. 35) expõe que "existe um amplo debate acadêmico sobre o que é exatamente o turismo, que elementos o compõem [...], 0 que originou múltiplas definições, cada uma delas destacando diferentes aspectos da mesma atividade"; e ainda salienta a necessidade de se criar um marco conceitual que atue como ponto de referência.

A questão epistemológica pode ser um fator que influencia na classificação da CDU, mas que não pode ser considerado como único. Para Panosso Netto (2003, p.58), "a epistemologia busca verificar o que é válido no conhecimento de determinado fenômeno [...] e a validade do que se conhece em uma determinada área; a epistemologia aplica-se a todas as disciplinas acadêmicas que conhecemos".

O aspecto epistemológico pode ser considerado como um fator auxiliar na classificação da área dentro da CDU, no entanto, todas as exposições anteriores indicam um sistema de classificação com algumas lacunas, prejudicando, assim, a recuperação da informação.

A percepção de um profissional da área vincula o turismo às definições mais abrangentes, visando o enquadramento adequado da atividade, enquanto fenômeno socioeconômico e objeto de estudo, no sistema de classificação bibliográfica analisado neste trabalho.

Vários são os modelos de representação do conhecimento; a dificuldade está em conseguir optar por aquele que retrate com maior precisão a área.

Como opção para melhor representar a área, sugere-se a construção de uma ontologia. Porém, diante de tantas implicações epistemológicas, é notória a complexidade de tal construção.

A CDU apresenta-se como uma estrutura hierárquica e semifacetada, no entanto, requer revisões periódicas para permitir maior flexibilidade na representação e classificação dos assuntos e áreas multi e interdisciplinares, como é o caso do Turismo.

Para fins de pesquisa em fontes de informação que utilizam este sistema, em análise anterior demonstrou-se alguns aspectos incompatíveis com a síntese formulada e, por sua vez, com algumas das definições apresentadas na área de Turismo.

Como foi descrito neste artigo, um modo de contemplar o Turismo é criar a classe 379, a qual poderia conter todas as associações do Turismo e representá-lo de forma pontual na CDU; uma vez que, na recuperação da informação, a classificação e a inclusão adequadas de termos que

10 autor insere a seguinte nota: "entende-se fenômeno, aqui, como aquilo que é dado ao conhecimento do intelecto. Eis a razão pela qual alguns autores definem o turismo como um fenômeno que envolve os aspectos social, cultural, psicológico, econômico". 
permitam ao usuário pesquisar dentro de uma determinada área do conhecimento configuram-se essenciais.

\section{Referências}

BARBOSA, A. P. Teoria e prática dos sistemas de classificação bibliográfica. Rio de Janeiro: IBBD, 1969.

BENI, M. C. Análise estrutural do turismo. 6.ed. São Paulo: Senac, 2001.

BRASIL. Ministério do Turismo. Turismo no Brasil: 2007-2010. Brasília, DF: MTUR, 2006. Disponível em: <http://institucional.turismo.gov.br/arquivos_open/diretrizes_manuais/pl anos_nacionais/Turismo_Brasil_2007_2010.pdf>. Acesso em: 03 jul. 2007.

CAMPOS, L; MENEZES, E. M. Classificação Decimal Universal - CDU: instruções e exercícios. 2 ed. Florianópolis: Ed. da UFSC, 1992.

COSTA, A. F. Classificações sociais. Leitura. Lisboa, v. 3, n. 2, p. 65-75, out. 1997/abr. 1998.

FONTOURA, M. T. W. T C. Classificação Decimal Universal (CDU): propriedades dos auxiliares comuns de propriedades. Morpheus - Revista Eletrônica em Ciências Humanas, v. 5, n. 9, 2006. Disponível em: <http://www.unirio.br/morpheusonline/numero09-2006/fontoura.htm>.

Acesso em: 28 ago. 2007.

JONCEW, C. C. A participação das fontes formais na qualificação da notícia. 310 f. Tese (Doutorado em Ciência da Informação) - Escola de Ciência da Informação, Universidade Federal de Minas Gerais, Belo Horizonte, $2005 . \quad$ Disponível em: <http://www.eci.ufmg.br/pcionline/viewissue.php?id=26>. Acesso em: 29 ago. 2007.

JOVICIC (referência completa)??? citado por REJOWSKI, M. Turismo e pesquisa científica. 2. ed. Campinas, SP: Papirus, 1998.

LAGE, B. H. G.; MILONE, P. C. Turismo: teoria e prática. São Paulo: Atlas, 2000.

LARA, M. L. G. A representação documentária: em jogo a significação. 133 f. Dissertação (Mestrado em Ciência da Informação) - Universidade de São Paulo, São Paulo, 1993.

LICKORISH, L. J.; JENKINS, C. L. Introdução ao turismo. Rio de Janeiro: Campus, 2000.

ORGANIZAÇÃO MUNDIAL DO TURISMO. Introdução ao Turismo. São Paulo: Roca, 2001.

ORTEGA, C. D. Informática documentária: estado da arte. São Paulo. 259 f. Dissertação (Mestrado em Ciência da Comunicação) - Escola de Comunicação e Artes, Universidade de São Paulo, São Paulo, 2002. 
PANOSSO NETTO, A. O problema epistemológico no turismo: uma discussão teórica. In: TRIGO, L. G.G.; PANOSSO NETTO, A. Reflexões sobre um novo turismo: política, ciência e sociedade. São Paulo: Aleph, 2003. cap. 2. p. 57-86.

REJOWSKI, M. Turismo e pesquisa científica. 2. ed. Campinas, SP: Papirus, 1998.

SILVA, O. P.; GANIM, F. Manual da CDU. Brasília: Briquet de Lemos, 1994.

UDC CONSORTIUM. Classificação Decimal Universal: edição-padrão internacional em língua portuguesa. Brasília: IBICT, 1997/1998. 2 v.

About Universal Decimal Classification and the UDC Consortium. 2007. Disponível em: <http://www.udcc.org/>. Acesso em: 29 set. 2007. 